\title{
Spatial, seasonal and long-term fluctuations of plankton in relation to hydroclimatic features in the English Channel, Celtic Sea and Bay of Biscay
}

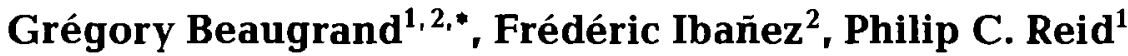 \\ ${ }^{1}$ Sir Alister Hardy Foundation for Ocean Science, The Laboratory, Citadel Hill, Plymouth PL1 2PB, United Kingdom \\ ${ }^{2}$ Laboratoire d'Océanographie biologique et d'Ecologie du plancton marin, ESA 7076, Station zoologique, BP 28, \\ 06230 Villefranche-sur-Mer, France
}

\begin{abstract}
Plankton collected by the Continuous Plankton Recorder (CPR) survey were investigated for the English Channel, Celtic Sea and Bay of Biscay from 1979 to 1995. The main goal was to study the relationship between climate and plankton and to understand the factors influencing it. In order to take into account the spatial and temporal structure of biological data, a three-mode principal component analysis (PCA) was developed. It not only identified 5 zones characterised by their similar biological composition and by the seasonal and inter-annual evolution of the plankton, it also made species associations based on their location and year-to-year change. The studied species have stronger yearto-year fluctuations in abundance over the English Channel and Celtic Sea than the species offshore in the Bay of Biscay. The changes in abundance of plankton in the English Channel are negatively related to inter-annual changes of climatic conditions from December to March (North Atlantic Oscillation [NAO] index and air temperature). Thus, the negative relationship shown by Fromentin \& Planque (1996; Mar Ecol Prog Ser 134:111-118) between year-to-year changes of Calanus finmarchicus abundance in the northern North Atlantic and North Sea and NAO was also found for the most abundant copepods in the Channel. However, the hypothesis proposed to explain the plankton/NAO relationship is different for this region and a new hypothesis is proposed. In the Celtic Sea, a relationship between the planktomic assemblage and the air temperature was detected, but it is weaker than for the English Channel. No relationship was found for the Bay of Biscay. Thus, the local physical environment and the biological composition of these zones appear to modify the relationship between winter climatic conditions and the year-to-year fluctuations of the studied planktonic species. This shows, therefore, that the relationship between climate and plankton is difficult to generalise.
\end{abstract}

KEY WORDS: Plankton - Long-term changes · Spatial variation · Seasonal fluctuation · Three-mode principal component analysis (PCA) · Winter climatic condition

\section{INTRODUCTION}

Study of large-scale spatial and temporal patterns in ecosystems is fundamental to understanding their natural variability. Their evolution depends on a large range of biotic and abiotic factors such as their species composition, local hydrodynamic characteristics and climatic parameters.

The Continuous Plankton Recorder (CPR) survey, which began in 1931, has examined the distribution of

•E-mail: gbea@wpo.nerc.ac.uk almost 400 planktonic taxa at an ocean basin scale in the North Atlantic. Observed long-term and spatial changes in the plankton seem to be strongly influenced by climatic features (Colebrook 1982, 1984, 1985, Fromentin \& Planque 1996). The North Atlantic Oscillation (NAO) appears to play a major role in determining the speed and direction of the wind and other climatic parameters and in governing certain hydrographic processes, which in turn influence the inter-annual evolution of plankton (Fromentin \& Planque 1996, Planque \& Taylor 1998, Reid et al. 1998). 
Until now, the connection between the NAO and plankton has been mainly studied in the northern North Atlantic and North Sea (Planque \& Taylor 1998. Reid et al. 1998). In addition, only a few studies have focussed on the importance of the local physical environment in the year-to-year evolution of plankton and its relationships with climatic factors. There are 2 main reasons for this: (1) the lack of appropriate data sets and (2) a lack of appropriate methodologies. Here, we studied a transect, the SA route sampled by a CPR, which traverses a number of different hydrographic regions including the strongly tidally mixed English Channel, the Ushant Front, the stratified shelf water of the Celtic Sea, and the shelf edge and deep oceanic water of the Bay of Biscay. Firstly, we identified geographical areas based on their biological composition and their temporal pattern at 2 relevant scales: a seasonal and year-toyear scale. Secondly, relationships between the yearto-year variability of plankton in each distinct zone was related to the long-term climatic changes expressed by the NAO index from Hurrell (1995) and the air temperature from the coarse long-term data sets in COADS (the Comprehensive Ocean Atmosphere DataSet). Finally, the effects of the local physical characteristics and biological composition of each zone were taken into account to better understand the factors influencing the long-term relationship between the plankton and the climatic parameters.

The determination of the geographical areas and the temporal study are based on a three-mode principal component analysis (three-mode PCA) that has been developed to enable the decomposition of the variance of species in a 3-dimensional matrix, which denotes here the variation of species in time and space. This technique has previously been used in psychometric studies by Tucker (1966) with the name 'three-mode factor analysis', in geology by Hohn (1979), in hydrobiology by Kroonenberg (1989), in agronomy by Bradford et al. (1990) and recently in genetics by Rincon et al. (1997).

\section{MATERIALS AND METHODS}

Sampling and preprocessing of data. Sampling: The SA route was sampled monthly from 1958 to 1995 by the CPR survey, but only the period between 1979 and 1995 was considered for this study because it corresponds to the whole transect from near Brighton in England to La Corona in Spain (Fig. 1). Sampling was realised by a high-speed plankton sampler (CPR) towed by merchant ships in the surface layer $(7$ to $8 \mathrm{~m}$ depth) with an average towing speed of $20 \mathrm{~km} \mathrm{~h}^{-1}$ (Hays 1994). Water enters the recorder through a square aperture of $1.62 \mathrm{~cm}^{2}$ and is filtered inside by a

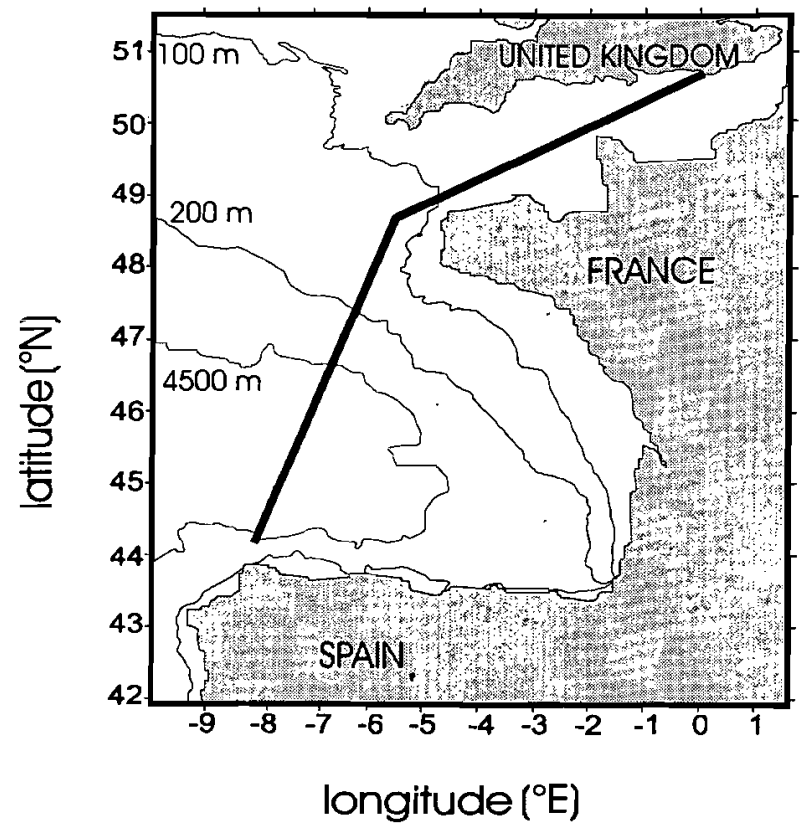

Fig. 1. SA route sampled monthly by CPR survey from 1979 to 1995

continuously moving band of silk which has an average mesh size of $270 \mu \mathrm{m}$ (Hays 1994). Then, the organisms are sandwiched by a second silk and stored in a tank with formalin. On return to the laboratory, the silk is unwound and cut into sections corresponding to $18.5 \mathrm{~km}$ of tow. Alternate samples are analysed under a microscope and the organisms identified and counted (Warner \& Hays 1994). In particular, the small and medium sized plankton species are counted from approximately copepodite stage 4 to adult, whereas the largest are counted from copepodite stage 1 to 6 , such as Calanus helgolandicus. For this study, in order to take into account the heterogeneity of sampling, the route was divided into 20 spatial intervals ('locations') containing the same number of observations (188 samples per interval). Of the 20 geographical classes, 17 were equal to $40 \mathrm{~km}$ and 3 were close to $70 \mathrm{~km}$ (first, middle and last class). Thus, $3760 \mathrm{CPR}$ samples were analysed.

Biological and hydroclimatic data. The CPR atlas (Oceanographic Laboratory of Edinburgh 1973) was used to select the most common species, e.g. having a minimal mean occurrence of 0.35 for each rectangle $\left(1^{\circ}\right.$ latitude $\times 2^{\circ}$ longitude) in the studied area (Table 1 ). This cut-off was to limit the number of species in the three-mode PCA and to decrease the number of zeros in the analyses. Data were log-transformed using a $\log (x+1)$ function (Colebrook 1975).

The NAO index from 1979 to 1995 was taken from Hurrell (1995). The NAO is the dominant mode of inter-annual changes in sea level pressure patterns 
Table 1. List of selected species

\begin{tabular}{|c|c|}
\hline Diatoms & $\begin{array}{l}\text { Thalassionema nitzschioides } \\
\text { Nitzschia delicatissima }\end{array}$ \\
\hline Dinoflagellates & $\begin{array}{l}\text { Ceratium fusus } \\
\text { Ceratium macroceros }\end{array}$ \\
\hline Copepods & $\begin{array}{l}\text { Acartia spp. } \\
\text { Centropages typicus } \\
\text { Calanus helgolandicus } \\
\text { Oithona spp. } \\
\text { Para-Pseudocalanus spp. } \\
\text { Clausocalanus spp. }\end{array}$ \\
\hline Gasteropods & Limacina sp. \\
\hline
\end{tabular}

over the North Atlantic region (Hurrell 1995, Planque \& Taylor 1998). The NAO index is the difference in normalised sea level pressures between Ponta Delgadas (Azores) and Akureyri (Iceland) during the winter season from December to March (Fig. 2).

Air temperatures, from 1979 to 1992 were taken from the COmprehensive Atmosphere Data Set (COADS; Woodruff et al. 1987). It is a global oceanographic dataset which includes a statistical summary of many climatic parameters for each month of each year using $2^{\circ}$ latitude $\times 2^{\circ}$ longitude boxes. To depict the relationships between air temperature and the NAO, means for the months December to March were calculated.

Numerical analysis. The CPR data set contains plankton counts located in time and space. In order to detect year-to-year variations in abundance, the mean of the abundance of each species for each location and each year was combined to generate a 3-way data matrix (11 species $\times 17$ years $\times 20$ locations). A similar table was built to hold the monthly means of abundance of each species for the whole period (11 species $\times 12$ months $\times 20$ locations). In oceanography, methods that allow the simultaneous analysis of complex tables are rare but in other areas of science such methods exist, e.g. the Co-inertia Analysis (Dolédec \& Chessel 1994) and the three-mode PCA (Tucker 1966, Beffy 1992, Hohn 1993). The latter method is developed here.

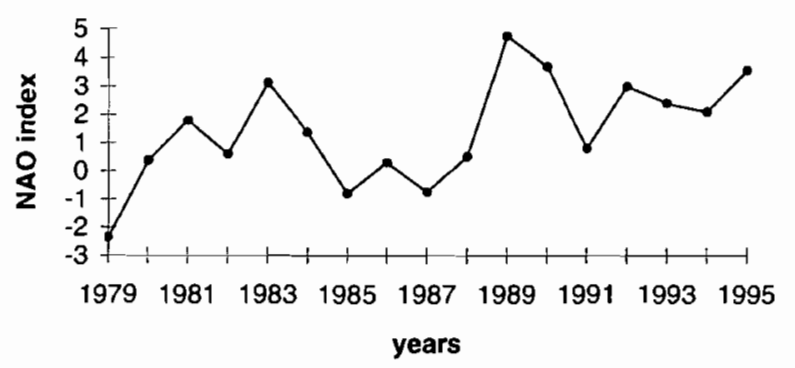

Fig. 2. Evolution of winter NAO index from 1979 to 1995 (Hurrell 1995)
Three-mode PCA: This analysis realises a classical PCA in each mode. In this paper, the first mode denotes the species space, $R^{p}$, the second mode the time, $R^{t}$, and the third mode the spatial space, $R^{s}$. Indeed, at the year-to-year scale during the first step, 3 classical PCAs are realised on the three 2-way tables with 11 species (columns) and 17 years $x$ 20 locations (rows), 17 years (columns) and 11 species $\times 20$ locations (rows), 20 locations (columns) and 11 species $\times 17$ years (rows). The multiregressive model of the PCA for a 3-way table $\boldsymbol{X}$ with P species, $\mathrm{T}$ times and $\mathrm{S}$ locations is:

$$
x_{i j k}=\sum_{p=1}^{\mathrm{P}} \sum_{t=1}^{\mathrm{T}} \sum_{s=1}^{\mathrm{S}} \boldsymbol{a}_{i p} \boldsymbol{b}_{j t} \boldsymbol{c}_{k s} \boldsymbol{g}_{p t s}+\boldsymbol{e}_{i, j, k}
$$

where $i=1, \ldots, 11$ species, $j=1, \ldots, 17$ years (or 12 months in the second analysis) and $k=1, \ldots, 20$ locations. $x_{i j k}$ corresponds to the values of an element at $i$, $j, k$ position of matrix $\boldsymbol{X}$, predicted by the results of 3 PCAs (in $R^{p}, R^{t}, R^{s}$ ). $a_{i p}, b_{j t}, c_{k s}$ represent the eigenvectors extracted in the PCA respectively in $R^{p}$ (11 total eigenvectors), $R^{t}$ (17 or 12 eigenvectors), and $R^{s}$ (20 eigenvectors), $\boldsymbol{g}_{\text {pts }}$ is called the core matrix. It explains the dominant variability in the 3-way table and estimates the interdependence between the modes (Beffy 1992, Hohn 1993).

If all eigenvectors are considered ( $P, T$ and $S$ ), the prediction Eq. (1) gives an accurate value for $\boldsymbol{X}$. If only a few principal components are used (reduction of the dimensional space), $\boldsymbol{X}$ is an estimation of the original data and an error term is associated with the equation.

Before analysis, the data were scaled for the 3 'classical' $^{\prime}$ PCAs to be run on the same total inertia. Classical scaling (Hohn 1979) was applied only for the species space $R^{p}$ to smooth the heterogeneity of the biological data. Thus, for each species the log-transformed abundances are scaled so their sum of squares equals 1 . In $R^{p}$, the matrix product observationsspecies by its transposition is similar to a correlation matrix, which is used to extract the eigenvectors. Here, for instance, with our 11 selected species, the sum of all the eigenvalues in any space is fixed at 11. Thus, the variance percentage of each mode is comparable and it constitutes the great advantage of this method. So, for instance, it is possible to know if the spatial variance is greater than the time variance.

Cumulative sums: In order to graphically represent changes between climatic and biological parameters, cumulative sums were applied (Ibañez et al. 1993, Lefevre-Lehoerff et al. 1995). First, each value of the series was subtracted by a reference value (here the mean), then the residuals were added progressively. This cumulated function is very sensitive to the changes of the local means values along the series (Ibañez et al. 1993). 


\section{RESULTS}

\section{Year-to-year variability}

\section{Three-mode PCA: eigenvectors}

For all modes, only representations in the first factorial plane are presented because the third dimension does not provide additional information. A cluster analysis, using the classification algorithm $(\beta=-0.3)$ of Lance \& Williams (1966) was also computed on the 3way tables, composed by Euclidean distance, in order to group the different variables to their respective mode.
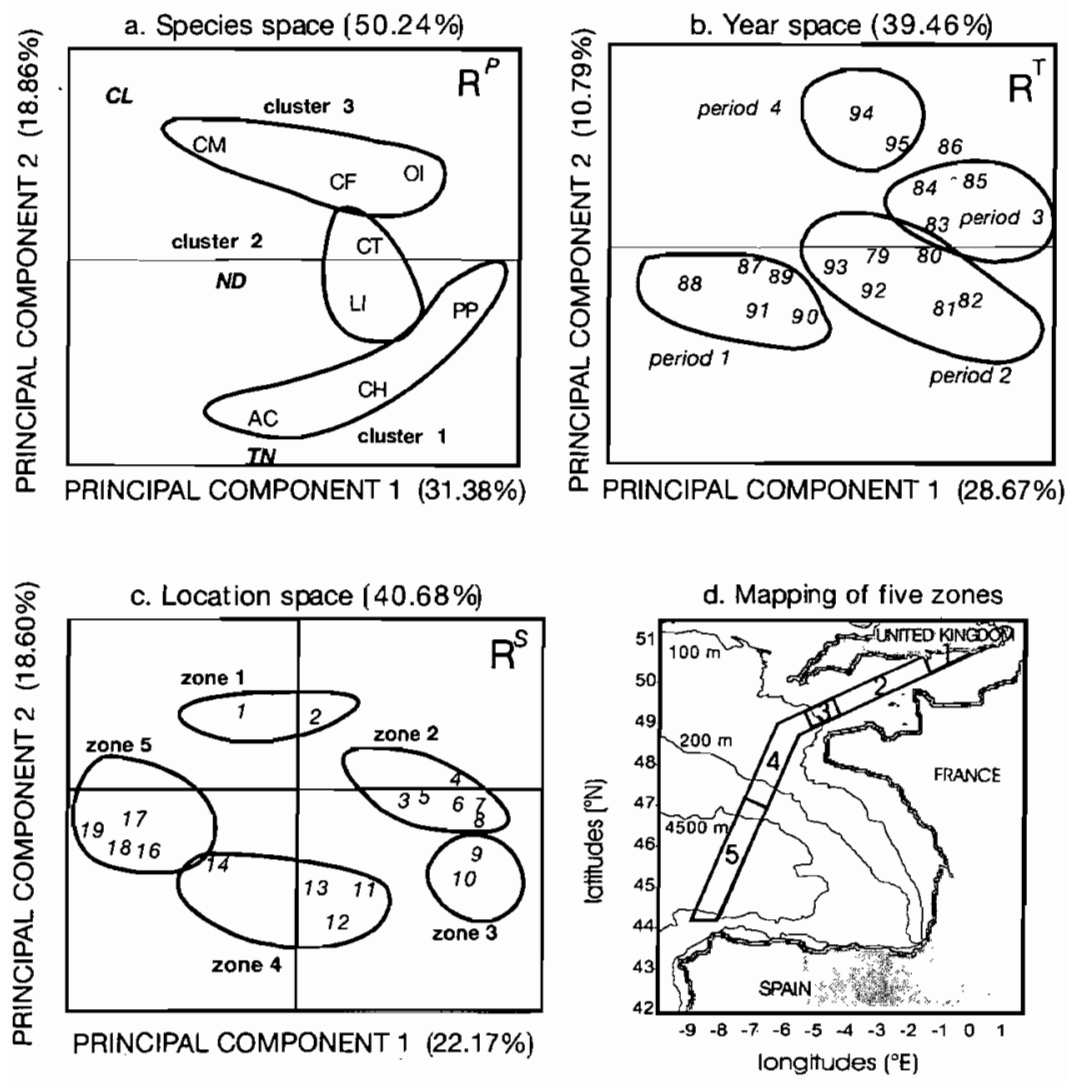

Fig. 3. Inter-annual variability. (a) Species mode $\left(R^{p}\right)$. Correlations between the species and the 2 first principal components location-year. Percentage of variance explained by the components is given in parentheses. A cluster analysis (see text) was used to arrive at 3 clusters and 3 isolated species (in italics). (b) Year mode $\left(R^{t}\right)$. Correlations between the years and the 2 first principal components specieslocation. The years were clustered into 4 periods except for 1986 (in italics). The temporal progress from year-to-year is visible for each period. (c) Location mode $\left(R^{s}\right)$. Correlations between the locations and the 2 first principal components species-year. The locations were clustered into 5 zones. (d) Mapping of 5 zones defined in the location mode. TN: Thalassionema nitzschioides; AC: Acartia spp.; $\mathrm{CH}$ : Calanus helgolandicus; PP: Para-Pseudocalanus spp.; ND: Nitzschia delicatissima; LI: Limacina sp.; CT: Centropages typicus; OI: Oithona spp.; CF: Ceratium fusus; CM: Ceratium macroceros; CC: Clausocalanus spp.
The species space, $R^{p}$ (species mode). All elements first eigenvector were positive, indicating that a cies (Fig 3a). Three species clusters were identified a a classification threshold of 0.56 . Three speciesNitzschia delicatissima, Thalassionema nitzschioides and Clausocalanus spp. - remained isolated after classification. Axis 1 of the scatter plot separates Clausocalanus spp., N. delicatissima, T. nitzschioides and Acartia spp. from species such as Oithona sp., Paraseudocalanus. Cluster 1 and $T$. nitzschioides are posed to cluster 3 and Clausocalanus spp. on axis 2 . The year space, $R^{t}$ (year mode). Four time clusters were found at a classification threshold of $0.52 ; 1986$ remained isolated (Fig. 3b). The clusters' comprise years, which are related in time. Axis 1 separates the periods 1 and 3 and axis 2 shows period 4 and year 1986 to be opposite to periods 1 and 2 .

The location space, $R^{s}$ (location mode). Five zones were found by classification at a threshold of 0.54 . Each zone is characterised by its particular bathymetry and hydrography (Fig. 3c,d). The first axis $(22.17 \%$ ) showed locations such as the western part of the Channel and the Celtic Sea to be opposite to locations in the Bay of Biscay, and the second axis $(18.50 \%)$ distinguished locations in the eastern Channel from the Celtic Sea.

\section{Three-mode PCA: principal components}

In Fig. 3a-c, the plots show a Guttman effect (Guttman 1958), indicating that the same factors affect both axes. Thus, results are presented only for the first principal component. For each space, the variables which are most correlated with axis 1 will have the strongest weight in the formation of the first principal component.

First principal component yearlocation (species mode, $R^{p}$ ). Strong year-to-year variations were found in the first 4 zones from English Channel to the Celtic Sea. In the Bay of Biscay year-to-year variability was much weaker (Fig. 4a). Low numbers 
occurred in period 1 , whereas periods 3,4 and the year 1986 had high abundance and period 2 was intermediate. Period 3 and year 1986 differed from period 4 in geographical pattern. From 1983 to 1986 an increase in species abundance took place in the whole of the study area, whereas from 1993 to 1995 high abundance levels were primarily located in the Celtic Sea.

First principal component species-location (time mode, $R^{t}$ ). This principal component exhibited a gradient along the transect (Fig. 4b). Clausocalanus spp. and species of cluster 3 were dominant in the Bay of Biscay and Celtic Sea and the species of cluster 2 predominated in the Ushant Front. Nitzschia delicatissima is located from the western English Channel to the Celtic Sea and cluster 1, while Thalassionema nitzschioides was more restricted to the Channel.

First principal component species-year (location mode, $R^{s}$ ). Two different patterns were found (Fig. $4 \mathrm{c}$ ). The diatoms and the species of clusters 1 and 2, which were found mainly in the Channel and Celtic Sea, showed year-to-year changes that were different than those of the species of cluster 3 and Clausocalanus spp., characteristic of the Bay of Biscay. These species showed an alternation of periods that may indicate the presence of cycles. Calanus helgolandicus seems to have weak year-to-year variations in this region, contrary to the other species.

\section{Three-mode PCA: core matrix}

Each of 3 PCAs was realised on the same percent of total variability, permitting a comparison of the variability in each mode. The mode which represented the greatest variability is the biological mode $(50.24 \%)$. At the year-to-year scale, the biological processes were

Fig. 4. Year-to-year variability. (a) Species mode $\left(R^{p}\right)$. Variability of the first principal component year-location. The grey shading indicates the intensity of the first component. The groups determined from the cluster analysis are indicated for years on the ordinate and for locations on the abscissa. (b) Year mode $\left(R^{t}\right)$. Variability of the first principal component species-location. The groups determined from the cluster analysis are indicated for species on the ordinate and for locations on the abscissa. (c) location mode $\left(R^{5}\right)$. Variability of the first principal component species-year. The groups determined from the cluster analysis are indicated for species on the ordinate and for years on the abscissa. Z1: northeastern English Channel; Z2: southwestern English Channel; Z3: Ushant Front; Z4: Celtic Sea; Z5: Bay of Biscay. TN: Thalassionema nitzschioides; AC: Acartia spp.; $\mathrm{CH}$ : Calanus helgolandicus; PP: Para-Pseudocalanus spp.; ND: Nitzschia delicatissima; LI: Limacina sp.; CT: Centropages typicus; OI: Oithona spp.i CF: Ceratium fusus; CM: Ceratium macroceros; CC: Clausocalanus spp. structured in time $(39.46 \%)$ and space $(40.68 \%)$ with almost the same strength (Fig. 3).

The core matrix allows a relationship to be established between biological, temporal and spatial processes. It summarises the main features in the graphs of eigenvectors (Hohn 1993). Only the greatest values of the core matrix can be analysed. The highest loading in the matrix $(0.927)$ in Table 2 reflects a high

a
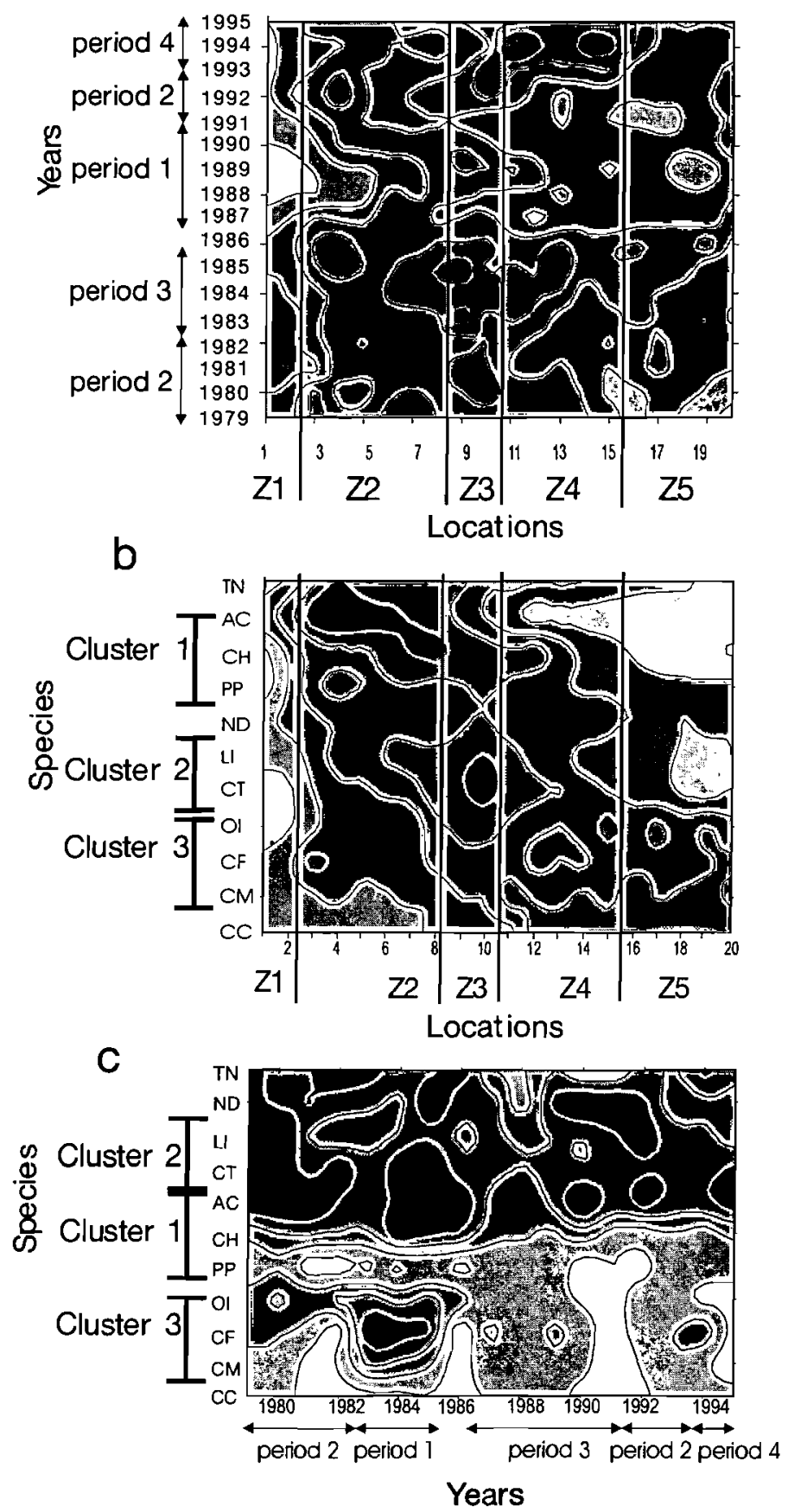
Table 2. Inter-annual scale. Core matrix stemes from the three-mode PCA of species-year-location table. The most important values used to relate the 3 modes are given in bold. PC: principal component

\begin{tabular}{|llcc|}
\hline & & PC1 species & PC2 species \\
\hline PC1 location & PC1 year & $\mathbf{0 . 7 8 5}$ & $\mathbf{0 . 9 2 7}$ \\
& PC2 year & $-\mathbf{0 . 0 7 4}$ & 0.080 \\
PC2 location & PC1 year & $-\mathbf{0 . 3 0 6}$ & 0.593 \\
& PC2 year & $\mathbf{0 . 6 5 3}$ & -0.238 \\
\hline
\end{tabular}

abundance of Para-Pseudocalanus, Oithona sp. and the species of cluster 2 (species mode) during the period 1984 to 1986 (time mode) in the western part of the English Channel (location mode). During these same periods, the loading of 0.785 indicates a greater abundance of species mostly localised in the Bay of Biscay.

\section{Year-to-year changes of species and climatic parameters}

In order to understand the origin of the year-to-year changes in species abundance, correlations between the first principal component year-location and the climatic parameters were calculated for each cluster analysis zone, which had been determined by the classification algorithm (Table 3). Significant Spearman correlations between the first principal component year-location, the NAO index and air temperature were found for the English Channel (zones 1 and 2). The use of the cumulative sum algorithm showed strong negative relationships for the Channel and the Celtic Sea (not detected in the calculation of the Spearman correlation coefficient on the original data) although in the Bay of Biscay the relationship seems to be positive (Fig. 5). However, in this last zone, the Spearman correlation coefficient showed no relationship between variations of plankton and climate parameters $(r=0.26)$
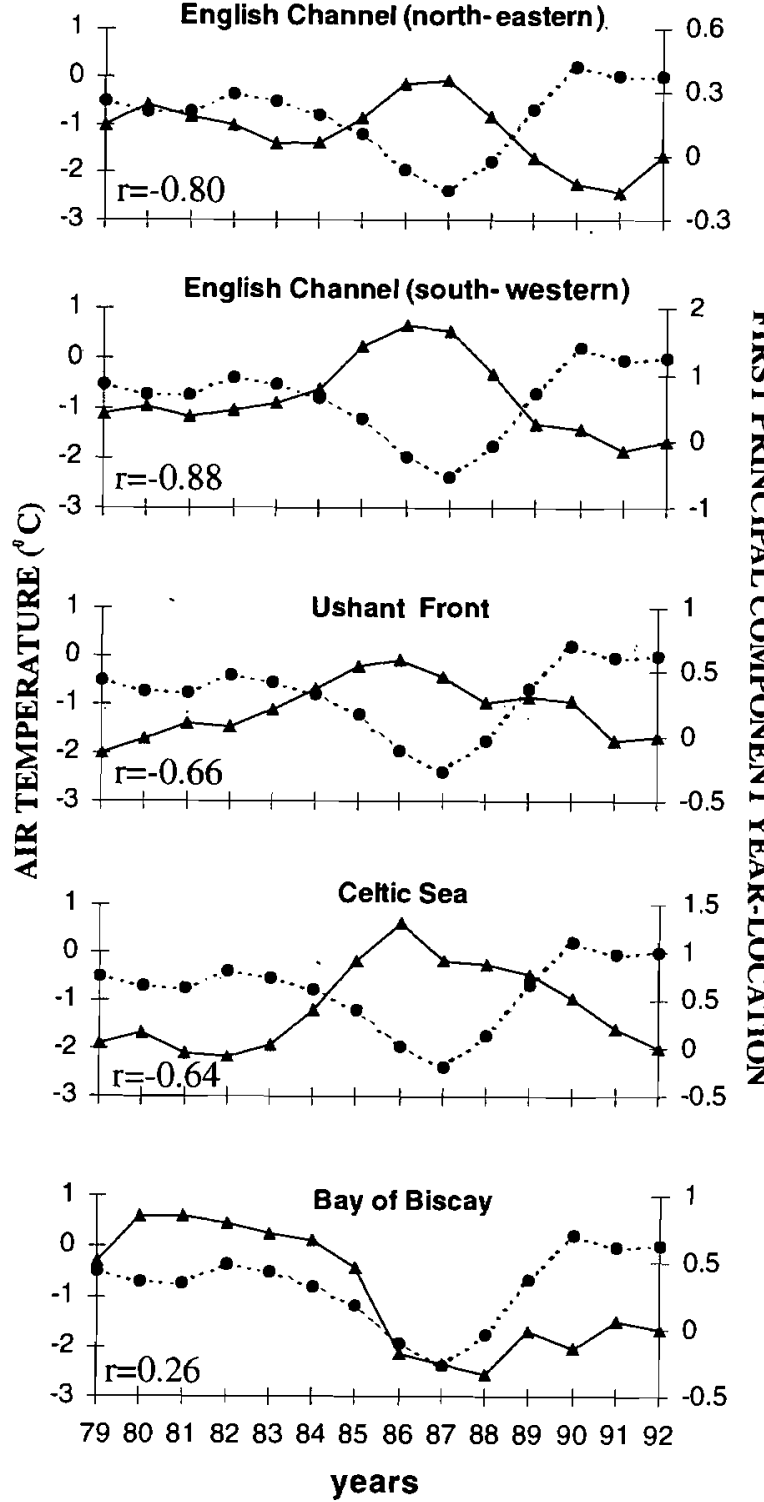

Fig. 5. Chronological series of air temperature $(\bullet)$ and the first principal component year-location ( $\mathbf{\wedge}$ ) after cumulative sums treatment for each zone by classification in the location space. The spearman correlation coefficients are indicated to give an idea of the strength of the relationships
Table 3. Correlations between the first principal component year-location into each zone defined by the cluster analysis in the species space and the climatic parameters. "Significant correlation at a threshold of $2 \%$. " Significant correlation at a threshold of $1 \%$. Monte Carlo test: 50000 simulations

\begin{tabular}{|c|c|c|c|}
\hline & $\begin{array}{l}\text { NAO } \\
(n=17)\end{array}$ & $\begin{array}{l}\text { Air humidity } \\
\quad(n=14)\end{array}$ & $\begin{array}{l}\text { Air temperature } \\
\qquad(\mathrm{n}=14)\end{array}$ \\
\hline Northeastern English Channel & $-0.42^{*}$ & $-0.68^{* *}$ & $-0.74 \cdots$ \\
\hline Southwestern English Channel & $-0.52^{*}$ & $-0.71 *$ & $-0.71 *$ \\
\hline Ushant Front & -0.03 & -0.33 & 0.14 \\
\hline Celtic Sea & 0.04 & $-0.57^{\circ}$ & -0.38 \\
\hline Bay of Biscay & -0.08 & -0.17 & 0.1 \\
\hline
\end{tabular}

\section{Seasonal variability}

Months were clustered into 3 periods: April-May (spring bloom), October-March (low abundance), and June-September (intermediate). The species clusters were similar to those found in the year-to-year analysis. Geographical clustering at a seasonal scale differs slightly from the interannual pattern shown in Fig. 3d. Cluster 4 approximately defines the posi- 


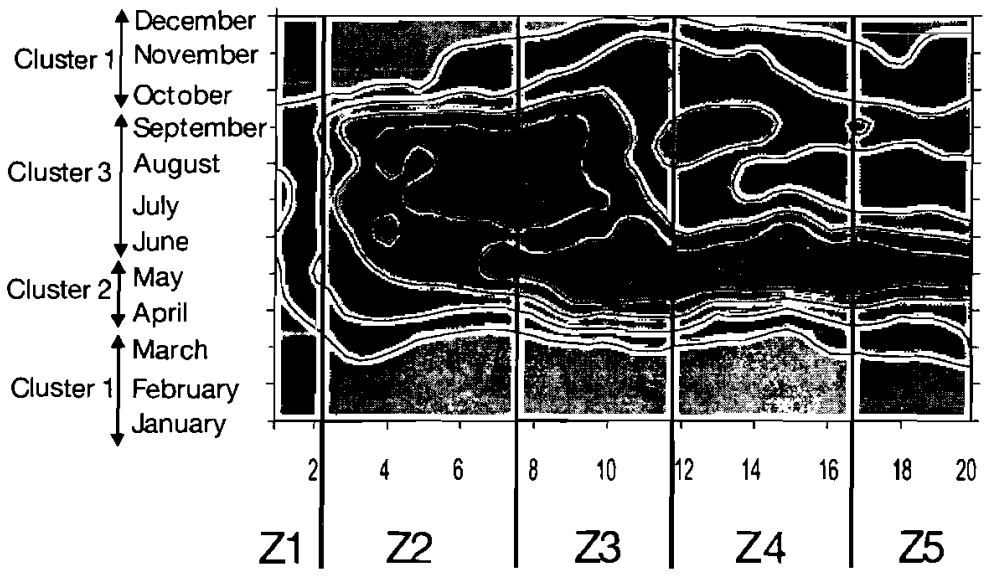

Fig. 6. Seasonal variability, species mode $\left(R^{p}\right)$. Variability of the first principal component month-location. The grey shading indicates the intensity of the first component. The groups determined from the cluster analysis are indicated for months on the ordinate and for locations on the abscissa. Z1: Northeastern Channel, Z2: Central Channel, Z3: Southwestern Channel and Northeastern Celtic Sea, Z4: Southern Celtic Sea, Z5: Bay of Biscay

Ushant Front, where effects are evident (Fig. 3a). The Ushant tidal front begins to form in April (Le Fèvre 1986) and is well established from June to the end of summer (Sournia et al. 1990). Phytoplankton biomass is high in the front (Viollier et al. 1987) but its implications for zooplankton abundance remain little known (Sournia et al. 1990). From our results, it seems that at the inter-annual scale abundance of zooplankton is influenced by this front (mainly species clusters 1 and 2).

At the year-to-year scale, the region can be divided into 2 distinct ecological areas on the basis of their biological composition, year-to-year variations of planktonic species and their relationships with the climatic parameters. In the first area, there is a clear gradient in the occurrence of the species (Fig. 3b). The most representative are the species of the clusters 1 and 2 and the diatoms, which could be favoured by the strong mixing of the area. In the Celtic

tion of the continental margin and the zone of the Ushant Front is larger taking into account the northern part of the Celtic Sea and the southern part of the Channel.

Only the first principal component month-location is presented and shows the seasonal variations for the species with the closest correlation to axis 1 in each geographical zone (Fig. 6). The seasonal maximum in the Channel was larger than in the Celtic Sea and Bay of Biscay. The seasonal maximum in May for the Ushant Front (zone 3) and the part over the continental slope (zone 4) was the highest. In the Channel, the value of the principal component was high from May to September in contrast to that for the Celtic Sea and particularly that for the Bay of Biscay, which has 2 maxima, in May and September. In summer, the value of the first principal component decreased in zones 4 and 5 .

\section{DISCUSSION}

The SA route crosses several hydrographic features such as the Ushant Front and the shelf edge front. On the shelf edge, when the thermocline is established (from May to September), internal waves interacting with the wind bring nutrients to the surface (Mazé et al. 1986). It is possible that the high abundance seen during the spring at the seasonal scale (zone 4 in Fig. 6) originates from this phenomenon. However, our results show that this process seems to have no effect on production at an inter-annual scale, in contrast to the
Sea, cluster 3 and Clausocalanus spp. appear. Over the shelf (first 4 zones, Fig. 3d), the year-to-year variability in plankton abundance is negatively related to winter climatic conditions, a result shown by Colebrook (1985) for the North Sea. From the northeastern English Channel to the Celtic Sea the decreasing gradient in the correlation between plankton abundance and climatic factors suggests that the effect of climate is stronger when the sea becomes shallower (Table 3, Fig. 5). In fact, over the English Channel (zones 1 and 2), the impact of winter climatic conditions is stronger than over the Ushant Front (zone 3) and the Celtic Sea (zone 4). To explain the difference between the Channel and the limited area of the Ushant Front, it is hypothesised that the local physical factors of the Ushant Front might diminish the relationships between climate and plankton. The second area, the Bay of Biscay (zone 5), is mainly characterised by copepods Clausocalanus spp. and Oithona spp. and the dinoflagellates favoured in more stratified waters. This area shows a pattern of lower year-to-year changes that do not appear to be related to the climatic parameters. This pattern even seems to be positively related to climatic conditions, although the relationship was not statistically significant. The lack of any relationship between the climate indices and plankton in the Bay of Biscay could be a consequence of a reduced influence of the NAO in this zone (Planque \& Taylor 1998).

During a strong NAO, westerly winds are reinforced over the North Atlantic and over the Celtic continental shelf and the English Channel (Planque \& Taylor 


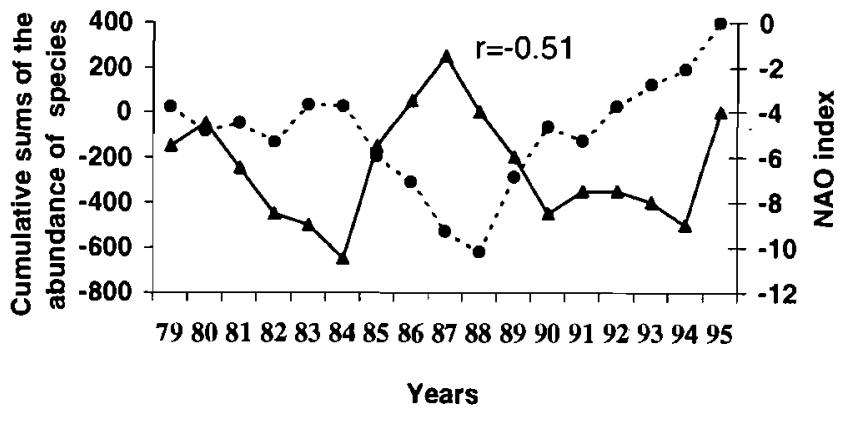

Fig. 7 Chronological series of the species abundance belonging to cluster 3 and Clausocalanus spp. (in the Bay of Biscay $(\triangleleft)$ in the English Channel and the NAO index (•) after cumulative sums treatinent. The spearman correlation coefficient is indicated to give an idea of the strength of the relationships

1998). The resulting high wind stress increases mixing of the surface layer, adding to tide-induced turbulence in shallow regions. Stronger westerly winds might also lead to an increase of oceanic species in the Channel by advection (cluster 3 and Clausocalanus spp.). However, Fig. 7, which represents the cumulative sums of abundance of Bay of Biscay species in the English Channel and the NAO index, shows that the abundance of these species does not increase during a high NAO, but it actually decreases. This indicates that the lower abundance noted in the English Channel during high NAO periods is not due to advection. There are other possible mechanisms that have already been hypothesised to explain relationships between the NAO and plankton, particularly in the North Sea and the northern North Atlantic, including changes in primary production and zooplankton and modification of biotic interactions (Fromentin \& Planque 1996, Planque \& Taylor 1998). In the Channel, where there is a statistically significant relationship connecting the $\mathrm{NAO}$, air temperature and plankton (Table 3), it is hypothesised that the wind-induced turbulence may play an important role. It is known that turbulence has a positive effect on zooplankton, particularly the copepods, the main species in the Channel (species cluster 1, Centropages typicus and Oithona spp.) allowing an increase in the contact rate between prey and predator (Rothschild \& Osborn 1988). However, if this hypothesis were valid here, the relationship between the NAO and plankton would be positive. This seems to be the case in the Bay of Biscay although no statistical link was detected by the Spearman correlation coefficient.

Small-scale turbulence changes the behaviour of copepods, such as 'slow' and 'fast' swimming (Costello et al. 1990, Margalef 1997). In particular, the intensity and pattern of swimming behaviour changes and it has been shown that the time allocated to 'slow swim- ming', i.e. feeding, increases with turbulence even when food is not present (Marrasé et al. 1990, Saiz \& Alcaraz 1992). High turbulence will thus cause an increase in total metabolism (Alcaraz et al. 1994). In addition, our results show that during a high NAO pattern there was also an increase in air temperature (Spearman correlation coefficient $\mathrm{r}=0.76, \mathrm{p}<1 \%$ ) and hence sea temperature, which would lead to an increase in metabolism (Alcaraz et al. 1994). These facts indicate that the copepods must increase their nutrition to compensate for the energetic losses that occur in an unfavourable winter environment. Turbulence may also increase the feeding rate (MacKenzie \& Legget 1991, Saiz et al. 1992, Sundby et al. 1994) but this augmentation may be insufficient to compensate for turbulence-induced losses. This hypothesis is emphasised by the work of Saiz et al. (1992), who observed that turbulence decreases the number of eggs laid by a female. For planktonic copepods, it is commonly accepted that the rate of egg production by females is directly related to the amount of food ingested (Kiørboe et al. 1985, Berggreen et al. 1988, Poulet et al. 1995) and constitutes a good estimator of the energetic balance of copepods (Alcaraz 1997). Wind-induced turbulence and NAO-induced higher temperature during winter reinforces the energetic imbalance of copepods and is likely to decrease their fecundity.

The consequences of the micro-scale effects discussed above are (1) that the mortality rate of copepods increases, which translates into a decrease of the overwintering stock, and (2) that female fecundity will diminish, implicating a delay and reduction in the intensity of the spring bloom.

The core matrix identifies the highest variability in the original 3-dimensional matrix and distinguishes the major features relating to temporal, spatial and biological modes. The high abundance of zooplankton found during 1984 to 1986 , mainly in the English Channel and especially for copepod species of clusters 1 and 2, constitutes the main result established by this method. These years, which correspond to an average NAO index, constitute optimal conditions for zooplankton to balance energetic gains and losses (Fig. 2). Mortality rates might have decreased during these years, allowing the maintenance of high overwintering stocks and an increase in the fecundity of copepods in the spring.

\section{CONCLUSION}

The NAO event plays a major role in governing the state of wind, temperature and others climatic factors, which have direct effects on the year-to-year variations 
of plankton abundance over the continental shelf of the Celtic Sea and especially in the English Channel. The negative relationship between the NAO and $\mathrm{Cal}$ anus finmarchicus found by Fromentin \& Planque (1996) in the northern North Atlantic can be extented to the most abundant copepods in the Channel (species cluster 1, Oithona spp. and Centropages typicus for this study). Several mechanisms have already been proposed to explain a link between the NAO and plankton. These include advection, modification of biotic interactions, impact on bottom-up control, delay of the spring bloom and (in this study) the effects of turbulence. New numerical analysis procedures like three-mode PCA have been developed to interpret the large space/time CPR database. This method has made it possible to sort information into 3-way tables enabling an improved analysis of time-space structured biological data. It permits the detection of regions based on their biological composition and year-to-year change (mode location), the identification of species associations related to both interannual and spatial changes of species (mode species) and the ordination of years based on species and locations (mode year). Applied at the annual and inter-annual scale, the method has demonstrated that it is important to take into account large-scale events in order to understand variability of ecosystems at smaller scales.

Acknowledgements. The authors are grateful to all the past and present members and supporters of the Sir Alister Hardy Foundation for Ocean Science, whose continuous efforts have allowed the long-term establishment and maintenance of the CPR data set. They also thank Dr Michael Ed. Hohn for his advice in the programming of the three-mode PCA and the anonymous referees for comments on the manuscript.

\section{LITERATURE CITED}

Alcaraz M (1997) Copepods under turbulence: grazing, behavior and metabolic rate. Sci Mar 61:177-195

Alcaraz M, Saiz E, Calbet A (1994) Small-scale turbulence and zooplankton metabolism: effects of turbulence on hearthbeat rates of planktonic crustaceans. Limnol Oceanogr 39:1465-1470

Beffy JL (1992) Application de l'analyse en composante principale à trois modes pour l'étude physico-chimique d'un écosystème lacustre d'altitude: perspectives en écologie. Rev Stat Appl 40:37-56

Berggreen U, Hansen B, Kiørboe T (1988) Food size spectra, ingestion and growth of the copepod Acartia tonsa: implication for the determination of copepod production. Mar Biol 99:341-352

Bradford KE, Kroonenberg PM, Delacy $1 \mathrm{H}$, Lawrence PK (1990) Multiattribute evaluation of regional cotton variety trials. Theor Appl Genet 79:225-234

Colebrook JM (1975) The Continuous Plankton Recorder survey: automatic data processing methods. Bull Mar Ecol 8: 123-142
Colebrook JM (1982) Continuous Plankton records: seasonal variation in the distribution and abundance of plankton in the North Atlantic Ocean and the North Sea. J Plankton Res $4: 435-462$

Colebrook JM (1984) Continuous Plankton Records: overwintering and annual fluctuations in the abundance of zooplancton. Mar Biol 83:261-265

Colebrook JM (1985) Sea surface temperature and zooplankton, North Sea, 1948 to 1983 . J Cons Int Explor Mer 42 : 179-185

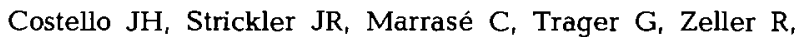
Freise AT (1990) Grazing in a turbulent environment: behavioural response of a calanoid copepod, Centropages hamatus. Proc Natl Acad Sci USA 87:1648-1652

Dolédec S, Chessel D (1994) Co-inertia analysis: an alternative method for studying species-environment relationships. Freshw Biol 31:277-294

Fromentin JM, Planque B (1996) Calanus and environment in the eastern North Atlantic. II. Influence of the North Atlantic Oscillation on C. finmarchicus and C. helgolandicus. Mar Ecol Prog Ser 134:111-118

Guttman L (1958) What lies ahead for factor analysis. Educ Psychol Meas 18:497-515

Hays GC (1994) Mesh selection and filtration efficiency of the Continuous Plankton Recorder. J Plankton Res 16: 403-412

Hohn ME (1979) Principal component analysis of three-way tables. Math Geol V 11:611-626

Hohn ME (1993) Principal component analysis of three-way data. Computers in geology. In: Davis JC, Hertzfeld UC (eds) Computers in geology -25 years of progress. Oxford University Press, New York, p 181-194

Hurrell J (1995) Decadal trends in the North Atlantic Oscillation: regional temperatures and precipitation. Science 269:676-679

lbañez F, Fromentin JM, Castel J (1993) Application de la méthode des sommes cumulées à l'analyse des séries chronologiques en océanographie. C R Acad Sci Paris Sci Vie/Life Sci 316:745-748

Kiørboe T, Mohlenberg F, Hambueger K (1985) Bioenergetics of the planktonic copepod Acartia tosa: relation between feeding, egg production and respiration and composition of specific dynamic action. Mar Ecol Prog Ser 26:85-97

Kroonenberg PM (1989) The analysis of multiple tables in factorial ecology. Ill. Three-mode principal component andlysis: 'analyse triadique complête'. Acta Oecol Oecol Gen $10: 245-256$

Lance GN, Williams WT (1966) A generalized sorting strategy for computer classification. Nature 212:218

Le Fèvre $J$ (1986) Aspects of the biology of frontal systems. Adv Mar Biol 23:163-299

Le Fèvre-Lehoerff G, Ibañez F, Poniz P, Fromentin JM (1995) Hydroclimatic relationships with planktonic time series from 1975 to 1992 in the North Sea off Gravelines, France. Mar Ecol Prog Ser 129:269-281

MacKenzie BR, Legget WC (1991) Quantifying the contribution of small-scale turbulence to the encounter rates between larval fish and their zooplankton prey: effects of wind and tide. Mar Ecol Prog Ser 73:149-160

Margalef R (1997) Turbulence and marine life. Sci Mar 61: 109-123

Marrasé C. Costello JH, Granata T, Strickler JR (1990) Grazing in a turlulent environment: energy, dissipation, encounter rates and efficacy of feeding currents in Centropages hamatus. Proc Natl Acad Sci USA 87:1653-1657

Mazé R., Camus Y, Le Tareau JY (1986) Formation de gradients thermiques à la surface de l'océan, au dessus 
d'un talus, par interactions entre les ondes internes et le mélange dû au vent. J Cons Int Explor Mer 42:221-240

Oceanographic Laboratory of Edinburgh (1973) Continuous Plankton Records: a plankton atlas of the North Atlantic and the North Sea. Bull Mar Ecol 7:1-174

Planque B, Taylor AH (1998) Long-term changes in zooplankton and the climate of the North Atlantic. ICES J Mar Sci 55:644-654

Poulet SA, Ianova A, Laabir M, Klein Breteler WCM (1995) Towards the measurement of secondary production and recruitment in copepods. ICES J Mar Sci 52:359-368

Reid PC, Planque B, Edwards M (1998) Is variability in the long-term results of the Continuous Plankton Recorder survey a response to climate change? Fish Òceanogr 7: 282-288

Rincon F, Johnson B, Crossa J, Taba S (1997) Identifying subsets of maize accessions by three-mode principal component analysis. Crop Sci 37:1936-1943

Rothschild BJ, Osborn TR (1988) Small-scale turbulence and plankton contact rates. J Plankton Res 10:465-474

Saiz E, Alcaraz M (1992) Free-swimming behaviour of Acartia clausi (copepoda: Calanoida) under turbulent water movement. Mar Ecol Prog Ser 80:229-236

Editorial responsibility: Otto Kinne (Editor),

Oldendorf/Luhe, Germany
Saiz E, Alcaraz M, Paffenhöfer GA (1992) Effects of smallscale turbulence on feeding and gross-growth efficiency of three Acartia species (Copepoda: Calanoida). J Plankton Res 14:1085-1097

Sournia A, Brylinski JM, Dallot S, Le Corre P, Leveau M, Prieur L, Froget C (1990) Fronts hydrologiques au large des côtes françaises: les sites-ateliers du programme Frontal. Oceanol Acta 13:413-438

Sundby S, Ellertsen B, Fossum P (1994). Encounter rates between first-feeding cod larvae and their prey during moderate to strong turbulent mixing. ICES J Mar Sci Symp 198:393-405

Tucker LR (1966) Some mathematical notes on three-mode factor analysis. Psychometrika 31:279-311

Viollier M, Sournia A, Birrien JL, Morin P (1987) Observations satellitaires du phytoplancton dans les zones de discontinuité géographique au large de la Bretagne. In: Océanographie spatiale. Oceanol Acta 7:51-56

Warner AJ, Hays GC (1994) Sampling by the Continuous Plankton Recorder survey. Prog Oceanogr 34:237-256

Woodruff SD, Slutz RJ, Jenne RL, Steurer PM (1987) A comprehensive ocean-atmosphere dataset. Bull Am Meteorol Soc 68:1239-1250

Submitted: February 23, 1999; Accepted: November 16, 1999 Proofs received from author(s): June 5, 2000 